\title{
The Synthesis of New Xylosyloligosaccharides by Transxylosylation with Aspergillus niger $\beta$-Xylosidase
}

\author{
Hideki Kizawa, ${ }^{*}$ Hirofumi ShINoYAMA ${ }^{* *}$ and Tsuneo Yasur ${ }^{\dagger}$ \\ Institute of Applied Biochemistry, University of Tsukuba, \\ Tsukuba, Ibaraki 305, Japan \\ Received July 23, 1990
}

\begin{abstract}
The synthesis of xylosyloligosaccharides from $\beta$-(1 $\rightarrow 4)$-xylobiose in the presence of D-mannose by transxylosylation with $\beta$-xylosidase from Aspergillus niger IFO 6662 was studied. At first, the transxylosylation products were separated by charcoal column chromatography in $5 \%$ ethanol elution into three peaks, P-1, P-2, and P-3. They were further separated on thin layer chromatography, and their three products, saccharides $\mathrm{O}-4, \mathrm{O}-5$, and $\mathrm{O}-\mathrm{N}$ were purified by preparative paper chromatography. Saccharides $O-4$ and $O-5$ were identified as $O-\beta$-D-xylopyranosyl-(1 $\rightarrow 4)$-D-mannopyranose and $O-\beta$-D-xylopyranosyl-(1 $\rightarrow 6)$-D-mannopyranose, respectively, by measurement of the degree of polymerization, specific rotation, acid hydrolysis, and methylation analysis. By ${ }^{1} \mathrm{H}-\mathrm{NMR}$ spectroscopy in addition to these analyses, saccharide $\mathrm{O}-\mathrm{N}$ was identified as $O-\beta$-D-xylopyranosyl$\left(1 \rightarrow 1^{\prime}\right)-\beta$-D-xylopyranose, a new nonreducing xylobiose.
\end{abstract}

In recent years, as new physiological actions and functions of oligosaccharides are found, many researchers have become interested in the preparation of useful oligosaccharides. In particular, using the enzymes which have a number of advantages, the high specificity for substrate and the mildness of reaction conditions etc., the synthesis of new oligosaccharides have been expected.

The $\beta$-xylosidase from Aspergillus niger IFO 6662 has a strong transxylosyl activity, and in our previous paper we reported the isolation and identification of a novel nonreducing disaccharide, $O-\beta$-D-xylopyranosyl- $\left(1 \rightarrow 1^{\prime}\right)-\beta$ $D$-xylopyranose produced by transxylosylation of $A$. niger $\beta$-xylosidase. ${ }^{1)}$ Shinoyama et al. have reported the enzymatic synthesis of various alkyl $\beta$-xylosides by application of the transxylosylation of this enzymes. ${ }^{2-4)}$ From these reports, $A$. niger $\beta$-xylosidase was supposed to have a broad specificity toward the hydroxyl groups of acceptors (alcohols or sugars).

To find the monosaccharides usable as acceptors, we did thin layer chromatography (TLC) of products formed from xylobiose by this enzyme in the presence of D-mannose, D-galactose, D-glucose, L-arabinose, or $\mathrm{D}$ fructose. When D-mannose, D-glucose, or $\mathrm{L}$-arabinose was used as an acceptor substrate, transxylosylation products were effectively synthesized.

In this paper we describe the isolation and identification of the three novel saccharides, two xylosylmannoses, and a nonreducing $x y-$ looligosaccharide produced using D-mannose as an acceptor substrate.

\section{Materials and Methods}

Materials. $\quad \beta-(1 \rightarrow 4)$-xylobiose (xylobiose) used as substrate was a gift from Towa Kasei Kogyo Co., Ltd.

* Present address: Intergrated Technology Laboratories, Takeda Chemical Industries, Ltd., Yodogawa-ku, Osaka 532, Japan.

** Present address: Department of Agricultual Chemistry, Faculty of Horticulture, Chiba University, Matsudo, Matsudo-shi, Chiba 271, Japan

$\ddagger$ To whom inquiries should be addressed. 
Preparation of the enzyme. Aspergillus niger IFO 6662 was cultivated in a medium of $2 \%$ xylan, $0.4 \% \mathrm{KH}_{2} \mathrm{PO}_{4}$, $1 \%\left(\mathrm{NH}_{4}\right)_{2} \mathrm{HPO}_{4}, 1 \%$ peptone, and $0.3 \%$ corn steep liquor at $30^{\circ} \mathrm{C}$ for 10 days on a shaker. After the culture, the culture broth was filtered through Toyo filter paper No. 2 (Toyo Chemical Co.). The filtrate was concentrated to suitable concentration by ultrafiltration and used as the enzyme solution throughout this work.

The xylan used in this experiment was a commercial hard wood xylan, "Sanpearl" supplied by the SanyoKokusaku Pulp Co. Ltd., which was a by-product from a mercerization process and insoluble in water.

Assay for $\beta$-xylosidase activity. The reaction mixture, consisting of $0.5 \mathrm{ml}$ of $0.02 \mathrm{M}$ phenyl $\beta$-D-xyloside in $0.1 \mathrm{M}$ acetate buffer $(\mathrm{pH} 4.4)$ and $0.5 \mathrm{ml}$ enzyme solution was incubated at $30^{\circ} \mathrm{C}$ for $15 \mathrm{~min}$. The reaction was stopped by the addition of $5 \mathrm{ml}$ of $0.55 \mathrm{M} \mathrm{Na}_{2} \mathrm{CO}_{3}$ and then $1.0 \mathrm{ml}$ of phenol reagent $(1 \mathrm{~N} \mathrm{HCl})$ was added to the reaction mixture and the concentration of liberated phenol was measured at $660 \mathrm{~nm}$.

One unit of enzyme activity was defined as the amount of enzyme that liberated $1 \mu \mathrm{mol}$ of phenol per min under the above experimental conditions.

Transxylosyl reaction with xylobiose and D-mannose. The reaction mixture containing $2.0 \mathrm{~g}$ xylobiose, $2.0 \mathrm{~g}$ D-mannose, and 260 units of enzyme solution in $80 \mathrm{ml}$ of $0.1 \mathrm{M}$ acetate buffer $(\mathrm{pH} 4.4)$ was incubated at $50^{\circ} \mathrm{C}$ for $1.5 \mathrm{hr}$. After the mixture was heated in a boiling water bath for $10 \mathrm{~min}$ to inactivate the enzyme, the proteinaceous precipitate was removed by ultrafiltration, and the filtrate was concentrated to $15 \mathrm{ml}$ under reduced pressure. The syrup thus obtained was chromatographed on a charcoal column.

Charcoal column chromatography. The above syrup $(2.3 \mathrm{~g} / 15 \mathrm{ml})$ resulting from the transfer reaction was adsorbed on an activated charcoal (Wako Jun Yaku Co.) column $(2.6 \times 38 \mathrm{~cm})$ and successively eluted with distilled water and 5,10 , and $30 \%(\mathrm{v} / \mathrm{v})$ ethanol. The flow rate was $48 \mathrm{ml} / \mathrm{hr}$ and $15-\mathrm{ml}$ fractions were collected.

High performance liquid chromatography (HPLC). HPLC was done on a column $(4.6 \mathrm{~mm} \times 25 \mathrm{~cm}$, TSK-Gel Amide 80, Tosoh Assoc., Inc.) at $60^{\circ} \mathrm{C}$ using a column oven (Gasukuro Kogyo, Nihon Dennetsu Keiki) with a Waters Associates M-45 instrument. The column was eluted by degassed acetonitrile-water $(8: 2, \mathrm{v} / \mathrm{v})$ at $1.0 \mathrm{ml} / \mathrm{min}$ and detection was done by a differential refractometer $\mathrm{R}-401$. The sample solution was filtrated through an ultrafiltration membrane (UFC 3T GCOO, Millipore Ltd.) before injection.

General methods. Total sugar was measured by the phenol-sulfuric acid method. ${ }^{5)}$ The compositions of monosaccharides were obtained by the hydrolysis of the transfer products for $2 \mathrm{hr}$ with $4 \%$ sulfuric acid or $10 \%$ trifluoroacetic acid (TFA) at $100^{\circ} \mathrm{C}$. The specific rotation of the transfer products was measured with a digital polarimeter model DIP-140 (Japan Spectroscopic Co., Ltd.). The degrees of polymerization (DP) of transfer products were estimated by the method of Timell. ${ }^{6)}$ In this procedure, a portion of the oligosaccharide is reduced with sodium borohydride and completely hydrolyzed with acid. Another portion is hydrolyzed without prior reduction and the reducing sugars in the two solutions are measured by the phenol-sulfuric acid method. The experimentally measured quotient $\mathrm{Q}$ of the reducing sugar content of the hydrolyzates before and after reduction will be DP/ $\mathrm{DP}-1$ and thus $\mathrm{DP}=\mathrm{Q} / \mathrm{Q}-1$.

Chromatography. Thin layer chromatography (TLC) was done on cellulose plates or silica gel plates $(20 \times 20 \mathrm{~cm}$, E. Merck). The solvent system used was 1-butanolpyridine-water $(6: 4: 3, \mathrm{v} / \mathrm{v} / \mathrm{v})$ or acetone-water-chloroform-methanol $(8: 0.5: 1: 1, \mathrm{v} / \mathrm{v} / \mathrm{v} / \mathrm{v})$. After development by three ascents with the solvent, sugars were detected by spraying with $p$-anisidine hydrochloric acid solution or $20 \%$ sulfuric acid in methanol and heating at $120^{\circ} \mathrm{C}$ or $150^{\circ} \mathrm{C}$ for $5 \mathrm{~min}$.

The purification of transxylosylation products was done by preparative PPC on Toyo filter paper No. 514A (Toyo Roshi Co., Ltd.), using the solvent system of 1butanol-pyridine-water $(6: 4: 3, \mathrm{v} / \mathrm{v} / \mathrm{v})$. After development by three ascents with the solvent, sugars were detected by spraying with $p$-anisidine hydrochloric acid solution and heating at $120^{\circ} \mathrm{C}$ for $5 \mathrm{~min}$.

Methylation analysis. Authentic samples and transfer reaction products were methylated by the method of Ciucanu and Kerek. ${ }^{7)}$ The methylated products were hydrolyzed at $100^{\circ} \mathrm{C}$ for $2 \mathrm{hr}$ with $4 \%$ sulfuric acid or $10 \%$ TFA and the partially methylated sugars were converted into their alditol acetates after reduction with $\mathrm{NaBH}_{4}$. The resultant alditol acetates were analyzed by gas liquid chromatography (GLC) ${ }^{8)}$ on a Shimadzu GC-7A gas liquid chromatograph, fitted with a flame ionization detector, using a glass column $(3 \times 1000 \mathrm{~mm})$ packed with $3 \%$ ECNSS-M on Gas Chrom Q (100-200 mesh, Nippon Kuromato Kogyo), at a column temperature of $160^{\circ} \mathrm{C}$. Nitrogen was used as the carrier gas at a flow rate of $50 \mathrm{ml} / \mathrm{min}$.

Nuclear magnetic resonance spectroscopy. An ${ }^{1} \mathrm{H}-\mathrm{NMR}$ spectrum was recorded at $200 \mathrm{MHz}$ with a superconduction nuclear magnetic resonance instrument AC 200 (Nihon Bruker Co., Ltd.). The sample was dissolved in solution in deuterium oxide. Chemical shifts were measured relative to the signal of 3-(trimethylsilyl)propionic-2,2,3,3$d_{4}$ acid, sodium salt (TSP), used as an internal standard. 


\section{Results}

HPLC analysis of transxylosyl reaction mixture of xylobiose in the presence of D-mannose by $A$. niger $\beta$-xylosidase

A sample of the transxylosyl reaction mixture of $2.0 \mathrm{~g}$ of xylobiose in the presence of

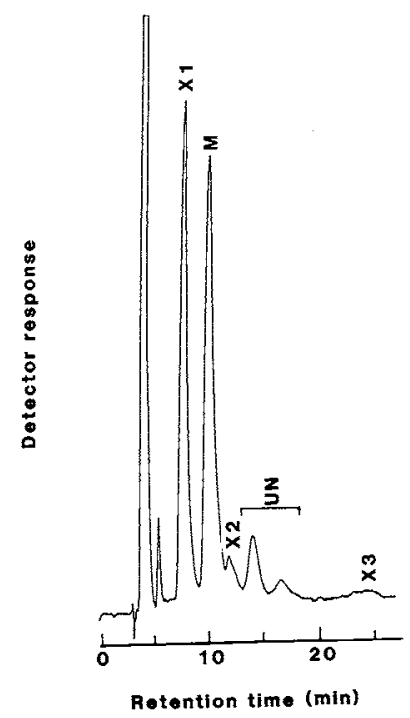

Fig. 1. HPLC Analysis of Transxylosyl Reaction Mixture.

The transxylosyl reaction was done as described under Materials and Methods. X1, xylose; M, mannose; X2, $\beta$-(1 $\rightarrow 4)$-xylobiose; UN, unknown products; $\mathrm{X} 3, \beta$ - $(1 \rightarrow 4)$ xylotriose.
$2.0 \mathrm{~g}$ of D-mannose with 260 units of $A$. niger $\beta$-xylosidase was analyzed by HPLC (Fig. 1). At least two unknown products thought to be transxylosylation products were observed.

\section{Charcoal column chromatography of transxy-} losylation products

The syrup $(15 \mathrm{ml})$ obtained from the transxylosyl reaction mixture was adsorbed and chromatographed on a charcoal column. Elution was first done with water to remove the remaining mannose and the hydrolysis product, xylose. Then the column was successively eluted with 5,10 , and $30 \%(\mathrm{v} / \mathrm{v})$ ethanol. As shown in Fig. 2, 5\% ethanol fractions were separated into three peaks (P-1, $\mathrm{P}-2$, and P-3). Total recovery from charcoal column chromatography of the transxylosylation products was calculated as approximately $90 \%$.

TLC and HPLC of transxylosylation products

Sugars contained in the main fractions of each of P, P-1, P-2, and P-3 were separated on TLC. The results in Fig. 3(A) showed that P-1, $\mathrm{P}-2$, and P-3 all contained sugars that were supposed to be transxylosylation products. The substances corresponding to the spots with $R x$ values of 0.53 (in P-1), $0.77,0.70$ (in P-2), and 0.84 and 0.68 (in P-3) on TLC are designated

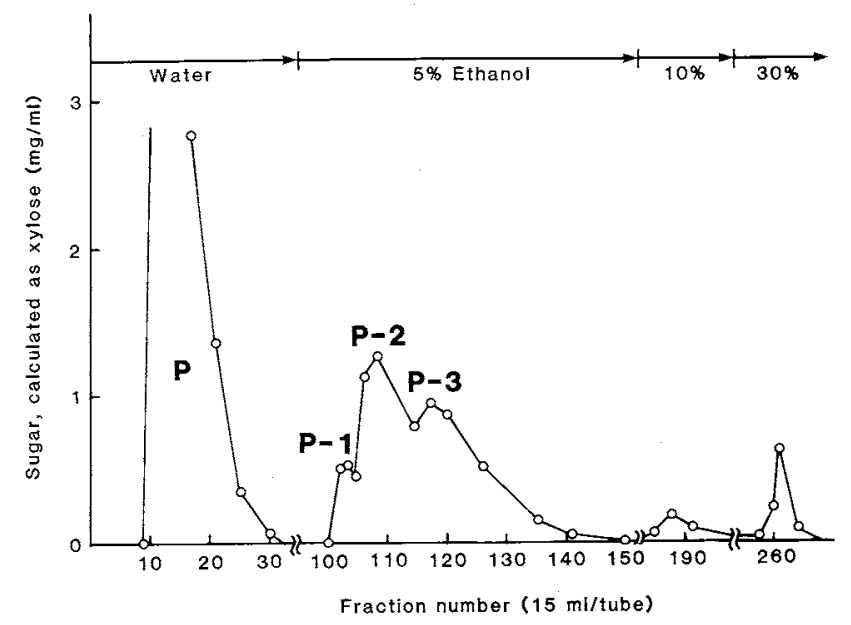

Fig. 2. Charcoal Column Chromatography of Transxylosylation Products.

The charcoal column chromatography of transxylosylation products was done as described under Materials and Methods. 

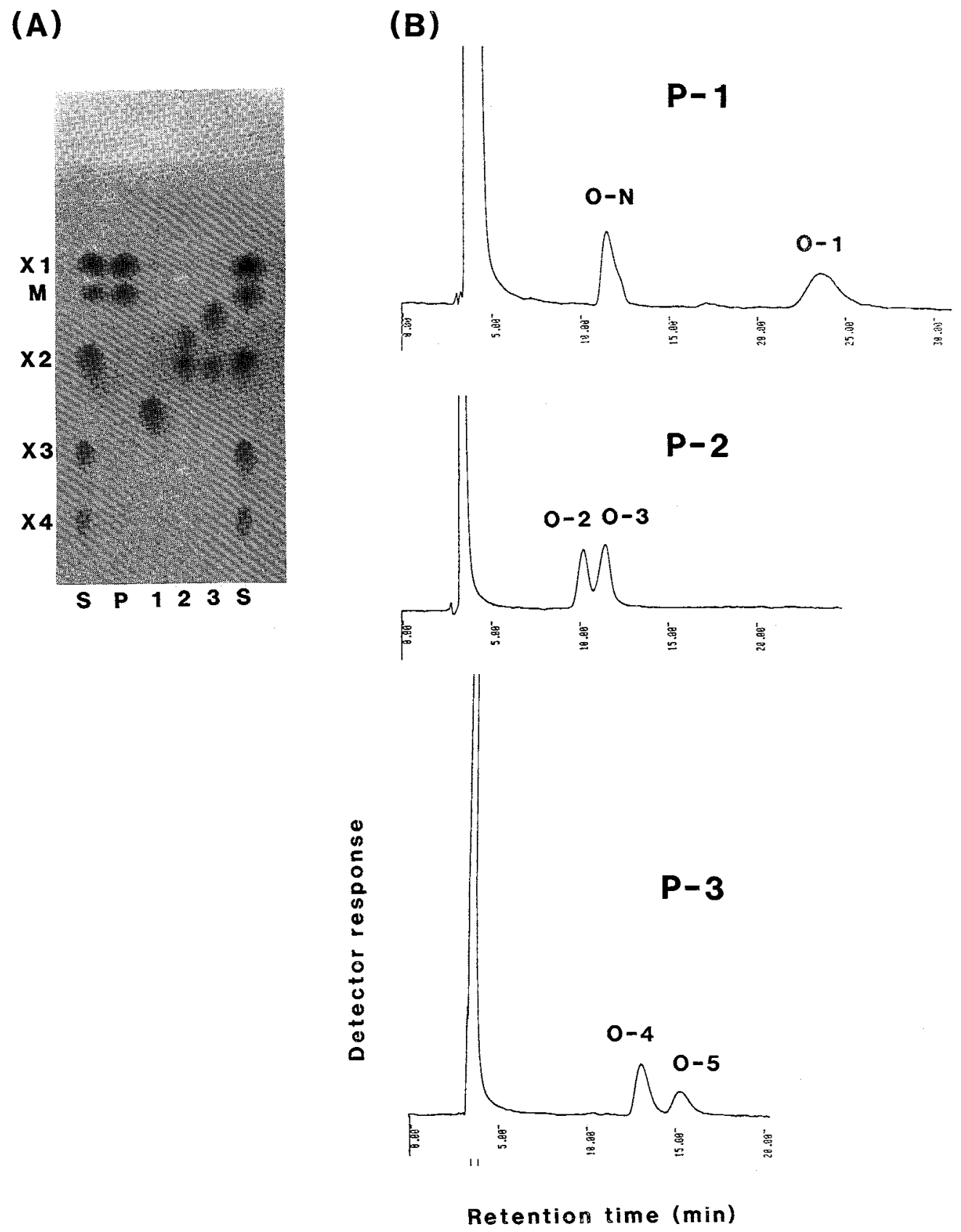

Fig. 3. Chromatograms of Transxylosylation Products by TLC and HPLC.

(A) TLC was done on a cellulose plate $(20 \times 20 \mathrm{~cm}$, E. Merck), using the solvent system of 1-butanol-pyridinewater $(6: 4: 3, \mathrm{v} / \mathrm{v} / \mathrm{v})$. After development by three ascents in the solvent, reducing sugars were detected by spraying with $p$-anisidine hydrochloric acid solution, followed by heating at $120^{\circ} \mathrm{C}$ for $5 \mathrm{~min} . \mathrm{S}$, standards (X1, xylose; $\mathrm{M}$, mannose; $\mathrm{X} 2, \beta$ - $(1 \rightarrow 4)$-xylobiose; $\mathrm{X} 3, \beta$ - $(1 \rightarrow 4)$-xylotriose; $\mathrm{X} 4, \beta-(1 \rightarrow 4)$-xylotetraose). $\mathrm{P}, \mathrm{I}$, 2 , and 3 represent $\mathrm{P}, \mathrm{P}-1, \mathrm{P}-2$, and $\mathrm{P}-3$ fractions of the charcoal chromatogram in Fig. 2. The $R x$ values and color of each spot are shown in Table I. (B) HPLC was done as described under Materials and Methods. 
as saccharides $\mathrm{O}-1, \mathrm{O}-2, \mathrm{O}-3, \mathrm{O}-4$, and $\mathrm{O}-5$, respectively.

Next, the same fractions from P-1, P-2, and P-3 were analyzed with HPLC. Though only one spot was detected in P-1 on TLC, two peaks were detected with HPLC (Fig. 3(B)). Reducing sugars develope color with $p$ anisidine hydrochloric acid solution as the spraying reagent, but not nonreducing sugars. Therefore, we thought that not only the saccharide $\mathrm{O}-1$ but also the other product (possibly a nonreducing sugar) were contained in P-1. This product undetected with $p$ anisidine hydrochloric acid solution, designated as saccharide $\mathrm{O}-\mathrm{N}$, was detected by $20 \%$ sulfuric acid in methanol (almost all organic substances detectable) (Fig. 4). The colors with $p$-anisidine hydrochloric acid solution and the $R x$ values of spots on TLC

\section{$\begin{array}{lll}\text { (a) } p \text {-anisidine } \mathrm{HCl} & \text { (b) } \mathrm{H}_{2} \mathrm{SO}_{4}\end{array}$}

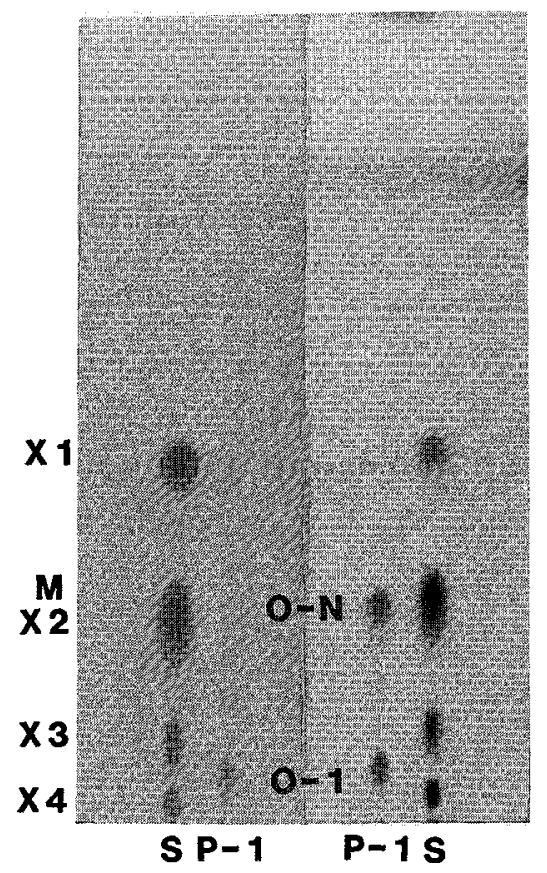

Fig. 4. Chromatograms of P-I (saccharides $\mathrm{O}-\mathrm{N}$ and O-1) by TLC.

TLC was done on a silica gel plate, using the solvent system of acetone-water-chloroform-methanol $(8: 0.5: 1: 1$, $\mathrm{v} / \mathrm{v} / \mathrm{v} / \mathrm{v}$ ) Sprayed with (a) $p$-anisidine hydrochloric acid solution; and (b) $20 \%$ sulfuric acid in methanol. The symbols are the same as Fig. 3. of the transxylosylation products are summarized in Table I. The saccharides O-4 and O-5 gave yellowish red, indicating that these two saccharides were heterooligosaccharides which consisted of xylose and mannose. We tried to isolate and identify the saccharides $\mathrm{O}-4, \mathrm{O}-5$, and $\mathrm{O}-\mathrm{N}$.

Table 1. $R x$ VAlues and COLORS For Transfer Products and the Other Sugars on TLC

\begin{tabular}{|c|c|c|}
\hline Sugar & $R x^{a}$ & Color $^{b}$ \\
\hline Saccharide O-1 & 0.53 & Dark yellow \\
\hline O-2 & 0.77 & Dark red \\
\hline O-3 & 0.70 & Dark red \\
\hline O-4 & 0.84 & Yellowish red \\
\hline O-5 & 0.68 & Yellowish red \\
\hline Xylose & 1.00 & Dark red \\
\hline Mannose & 0.91 & Dark yellow \\
\hline Xylobiose & 0.70 & Dark red \\
\hline
\end{tabular}

a On cellulose plates, using 1-butanol-pyridine-water $(6: 4: 3, v / v / v)$.

${ }^{b}$ Colored with $p$-anisidine hydrochloric acid solution.

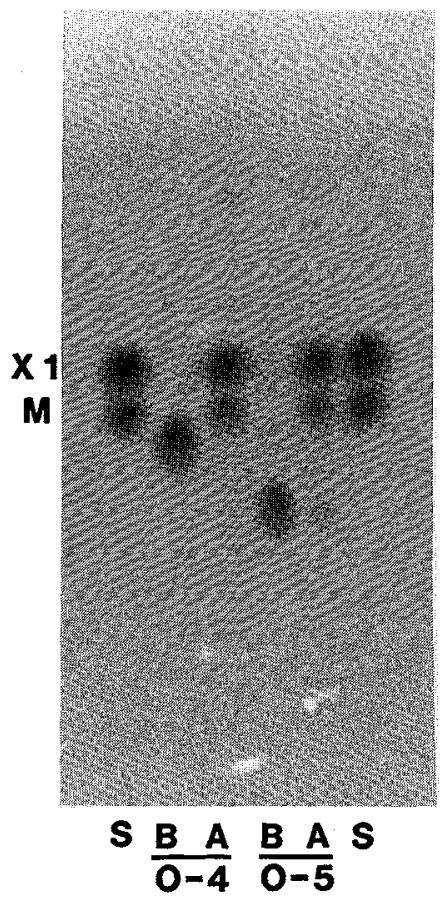

Fig. 5. Chromatogram of TFA Hydrolysis Products of Saccharides $\mathrm{O}-4$ and O-5 by TLC.

TLC was carried out as described in Fig. 3. S, standards (XI, xylose; M, mannose); B, before hydrolysis; A, after hydrolysis. 
The isolation and identification of saccharides $O-4, O-5$, and $O-N$

The fractions from P-1 and P-3 were collected and concentrated under reduced pressure and then purified by preparative PPC. The yields of the saccharides O-4, O-5, and $\mathrm{O}-\mathrm{N}$ were $27 \mathrm{mg}, 13 \mathrm{mg}$, and $4 \mathrm{mg}$, respectively (from a mixture of $2 \mathrm{~g}$ of xylobiose and $2 \mathrm{~g}$ of mannose).

As shown in Fig. 5, both TFA hydrolyzates of purified saccharides $\mathrm{O}-4$ and $\mathrm{O}-5$ gave xylose and mannose in approximately $1: 1$ molar ratio. On the other hand, the sulfuric acid hydrolyzate of purified saccharide $\mathrm{O}-\mathrm{N}$ gave only xylose. These results indicated that both saccharides $\mathrm{O}-4$ and $\mathrm{O}-5$ were xylosylmannoses and saccharide $\mathrm{O}-\mathrm{N}$ was a nonreducing xylooligosaccharide. The estimation of DP and

Table II. DEgreE of POLYMERIZATION AND Specific Rotation of Saccharides O-4, O-5 AND O-N

\begin{tabular}{ccc}
\hline $\begin{array}{c}\text { Transxylosylation } \\
\text { product }\end{array}$ & DP & {$[\alpha]_{\mathrm{D}}^{20}$} \\
\hline Saccharide $\mathrm{O}-4$ & 2 & $-41.1\left(c=0.9, \mathrm{H}_{2} \mathrm{O}\right)$ \\
$\mathrm{O}-5$ & 2 & $-26.8\left(c=0.5, \mathrm{H}_{2} \mathrm{O}\right)$ \\
$\mathrm{O}-\mathrm{N}$ & 2 & $-72.3\left(c=0.75, \mathrm{H}_{2} \mathrm{O}\right)^{a}$
\end{tabular}

a $[\alpha]_{\mathrm{D}}^{25}$. specific rotation of these products are shown in Table II.

The structural analysis of the transfer products was done by methylation analysis and the results are summarized in Table III. Hydrolysis products of methylated $\mathrm{O}-4$ gave 1,5-diacetyl-2,3,4-tri- $O$-methyl-D-xylitol and 1,4,5-triacetyl-2,3,6-tri- $O$-methyl-D-mannitol in approximately $1: 1$ molar ratio. Saccharide O-4 was, therefore, identified as $O-\beta$-Dxylopyranosyl-( $1 \rightarrow 4)$-D-mannopyranose. Hydrolysis products of methylated $\mathrm{O}-5$ gave 1,5-diacetyl-2,3,4-tri- $O$-methyl-D-xylitol and 1,5,6-triacetyl-2,3,4-tri- $O$-methyl-D-mannitol in approximately $1: 1$ molar ratio. Saccharide O-5 was, therefore, identified as $O-\beta$-D-xylopyranosyl- $(1 \rightarrow 6)$-D-mannopyranose. Hydrolysis product of methylated $\mathrm{O}-\mathrm{N}$ gave only $1,5-$ diacetyl-2,3,4-tri- $O$-methyl-D-xylitol, indicating that saccharide $\mathrm{O}-\mathrm{N}$ was a xylodisaccharide having a $\left(1 \rightarrow 1^{\prime}\right)$-linkage between the two xylosyl residues.

In addition, the ${ }^{1} \mathrm{H}-\mathrm{NMR}$ spectrum of saccharide $\mathrm{O}-\mathrm{N}$ is shown in Fig. 6. These signals support the deduction that both the two D-xylose moieties have the $\beta$-configuration. In the spectrum, no signals due to $\alpha$-anomeric protons were observed. From these data, saccharide $\mathrm{O}-\mathrm{N}$ was identified as $O-\beta-\mathrm{D}-$

Table III. Methylation Analysis of Saccharides O-4, O-5 and O-N

\begin{tabular}{|c|c|c|c|c|c|c|}
\hline $\begin{array}{c}\text { Alditol } \\
\text { acetate }^{a} \text { of }\end{array}$ & $\begin{array}{l}2,3,4-\text { Tri- } O- \\
\text { Me-D-Xyl } p^{b}\end{array}$ & $\begin{array}{c}\text { 2,3-Di-O- } \\
\text { Me-D-Xylp }\end{array}$ & $\begin{array}{c}\text { 2,3,4,6-Tetra-O- } \\
\text { Me-D-Manp } p^{c}\end{array}$ & $\begin{array}{l}\text { 2,3,6-Tri-O- } \\
\text { Me-D-Manp }\end{array}$ & $\begin{array}{l}\text { 2,3,4-Tri- } O- \\
\text { Me-D-Manp }\end{array}$ & $\begin{array}{l}\text { Mode of } \\
\text { linkage }^{d}\end{array}$ \\
\hline$t_{R}(\min )$ & 2.26 & 4.96 & 3.53 & 7.95 & 9.14 & \\
\hline \multicolumn{7}{|l|}{ Sugars } \\
\hline $\mathrm{X} 2$ & + & + & & & & $\mathrm{X} 1 \stackrel{p}{\longrightarrow} 4 \mathrm{X}$ \\
\hline $\mathrm{M}^{e}$ & & & + & + & & $\mathrm{M} 1 \stackrel{\beta}{\longrightarrow} 4 \mathrm{M}$ \\
\hline $0-4$ & + & & & + & & $\mathrm{X} 1 \stackrel{\beta}{\stackrel{\beta}{\longrightarrow}} 4 \mathrm{M}$ \\
\hline O-5 & + & & & & + & $\mathrm{X} 1 \stackrel{\beta}{\longrightarrow} 6 \mathrm{M}$ \\
\hline $\mathrm{O}-\mathrm{N}$ & + & & & & & $\mathrm{Xl} \stackrel{\beta \beta}{\rightarrow} 1 \mathrm{X}$ \\
\hline \multicolumn{7}{|c|}{ : } \\
\hline \multicolumn{7}{|c|}{$b \quad$ 2,3,4-Tri- $O$-Me-D-Xylp, 2,3,4-Tri- $O$-methyl-D-xylopyranoside. } \\
\hline \multicolumn{7}{|c|}{ c 2,3,4,6-Tetra- $O$-Me-D-Manp, 2,3,4,6-Tetra- $O$-methyl-D-mannopyranoside. } \\
\hline \multicolumn{7}{|c|}{ d $\mathrm{X}, \mathrm{M}$ and the numerals denote $\mathrm{D}$-xylopyranose, D-mannopyranose and the linkage positions, respectively. } \\
\hline
\end{tabular}




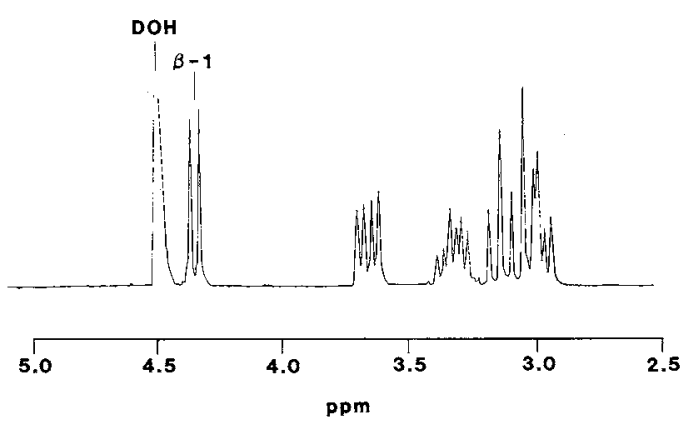

Fig. 6. ${ }^{1} \mathrm{H}-\mathrm{NMR}$ Spectrum of Saccharide O-N.

${ }^{1} \mathrm{H}-\mathrm{NMR}$ spectroscopy was done as described under Materials and Methods. DOH, deuterium hydroxide.

xylopyranosyl-(1 $\left.\rightarrow 1^{\prime}\right)-\beta$-D-xylopyranose.

\section{Discussion}

This paper describes the isolation and identification of three novel transxylosylation products from xylobiose in the presence of D-mannose. Their two products were xylosylmannoses, heterooligosaccharides consisting of xylose and mannose, and the other a nonreducing xylodisaccharide. The latter was identified as $O$ - $\beta$-D-xylopyranosyl- $\left(1 \rightarrow 1^{\prime}\right)-\beta$-Dxylopyranose according to the results of methylation analysis and ${ }^{1} \mathrm{H}-\mathrm{NMR}$ spectroscopy, etc. In our previous paper, we reported that this saccharide was produced from xylobiose only, in the absence of D-mannose by transxylosylation with $A$. niger $\beta$-xylosidase.

In Fig. 3, as the transxylosylation products in this study, besides the saccharide $\mathrm{O}-4, \mathrm{O}-5$, and $\mathrm{O}-\mathrm{N}$, saccharide $\mathrm{O}-1$ (in $\mathrm{P}-1$ ), $\mathrm{O}-2$, and O-3 (in P-2) had also been observed on TLC. Considering that the color of the spot on TLC with $p$-anisidine hydrochloric acid solution was dark yellow (Table I), saccharide O-1 was thought to be a mannooligosaccharide. Crude $\beta$-xylosidase from $A$. niger used in this study contains slight $\beta$-mannosidase activity. When the $R x$ value and the color of spot of the saccharide O-1 on TLC was compared with that of authentic $\beta$-( $1 \rightarrow 4)$-mannobiose, these colors were the same, but the $R x$ values were slightly different (data not shown). A product similar to saccharide $\mathrm{O}-1$ was found in the condensation reaction mixture of $\mathrm{D}$-mannose produced by this crude enzyme solution (data not published). These results suggested that saccharide $\mathrm{O}-1$ was a mannooligosaccharide other than $\beta$ - $(1 \rightarrow 4)$-mannobiose and was produced by the condensation reaction of $\mathrm{D}$-mannose with the contaminating $\beta$-mannosidase in $A$. niger crude enzyme. $A$. niger $\beta$-mannosidase probably has a high activity in the condensation reaction.

The $R x$ and the color of spot on TLC of saccharide $\mathrm{O}-3$ in Fig. 3 were the same as those for authentic xylobiose. Saccharide O-3 was thought to be $\beta$ - $(1 \rightarrow 4)$-xylobiose, the remaining substrate. For saccharide $\mathrm{O}-2$, the color of the spot was the same as those for $\beta-(1 \rightarrow 4)$ xylobiose; but the $R x$ was slightly different from it. Saccharide O-2 was thought to be a xylooligosaccharide other than $\beta$ - $(1 \rightarrow 4)$-xylobiose.

In this paper, we reported the isolation and identification of two new heterooligosaccharides, saccharides O-4 and O-5 produced from xylobiose and D-mannose. Previously, Chiba et al. had reported the formation of various heterooligosaccharides from maltose in the presence of various monosaccharides by transglucosylation with brewer's yeast $\alpha$ glucosidase and the comparative biochemical studies on $\alpha$-glucosidase. ${ }^{9,10)}$ As mentioned already, $A$. niger $\beta$-xylosidase can transfer a $\beta$-xylosyl moiety from $\beta$-xylosyl donors not only to the hydroxyl groups of xylose or xylooligosaccharides, but also to that of several alcohols or monosaccharides. This observation firmly indicates that $A$. niger $\beta$-xylosidase has a fairly broad specificity toward the acceptor substrates.

The application of the transxylosylation of this enzyme under the appropriate conditions may offer the possibility for the synthesis of new saccharides which have novel physiological functions, but it will be necessary to clarify further whether purified A. niger $\beta$-xylosidase has the properties described above or not. The studies on transxylosylation by purified enzyme will be reported elsewhere. 
Acknowledgment. The authors wish to thank Dr. Y. Gama and Dr. Y. Ishigami, National Chem. Lab. for Industry, for their help with the NMR examination.

\section{References}

1) T. Yasui, H. Kizawa, Y. Masada and H. Shinoyama, Agric. Biol. Chem., 53, 3381 (1989).

2) H. Shinoyama and T. Yasui, Nippon Nōgeikagaku Kaishi, 62, 1339 (1988).

3) H. Shinoyama, Y. Kamiyama and T. Yasui, Agric. Biol. Chem., 52, 2197 (1988).
4) H. Shinoyama and T. Yasui, Agric. Biol. Chem., 52, 2375 (1988).

5) M. Dubois, R. Gilles, J. K. Hamilton, P. A. Rebers and F. Smith, Anal. Chem., 28, 350 (1956).

6) T. E. Timell, Svensk Papperstid., 63, 668 (1960).

7) I. Ciucanu and F. Kerek, Carbohydr. Res., 131, 209 (1984).

8) I. Kusakabe, Y. Kamiyama and T. Yasui, Nippon Nōgeikagaku Kaishi, 51, 167 (1977).

9) S. Chiba and T. Shimomura, Agric. Biol. Chem., 33, 807 (1969).

10) S. Chiba and T. Shimomura, Agric. Biol. Chem., 33, 813 (1969). 